\title{
秎 \\ ORIGENS E IMPLICAÇÕES DO FUNCIONAMENTO DA CÂMARA DOS DEPUTADOS EM TEMPOS DE PANDEMIA: NOTAS SOBRE O SISTEMA DE DELIBERAÇÃO REMOTA (SDR) E O PAPEL DAS NOVAS TECNOLOGIAS
}

\author{
ORIGINS AND IMPLICATIONS OF HOUSE OF REPRESENTATIVES \\ ACTIVITY \\ IN PANDEMIC TIMES: NOTES ON THE REMOTE DELIBERATION \\ SYSTEM (SDR) AND THE ROLE OF NEW TECHNOLOGIES
}

\section{ORÍGENES E IMPLICACIONES DEL FUNCIONAMIENTO DE LA CÁMARA DE LOS DIPUTADOS EM TIEMPOS DE PANDEMIA: NOTAS SOBRE EL SISTEMA DE DELIBERACIÓN REMOTA (SDR) Y EL PAPEL DE LAS NUEVAS TECNOLOGÍAS}

\author{
Cristiane Corrêa Batista ${ }^{1}$ \\ Fabiano Guilherme Mendes Santos ${ }^{2}$
}

Resumo: O dia 13 de março marca o início do afastamento social no Brasil por conta da pandemia causada pela Covid-19. Quatro dias depois, a Câmara dos Deputados institui o Sistema de Deliberação Remota (SDR), realizando sua primeira sessão virtual no dia 25 do mesmo mês. O artigo tem por objetivo descrever o micro processo que viabilizou a retomada das atividades de plenário da Câmara tão rapidamente. Através de respostas a questionários semi-estruturados aplicados a atores chaves no processo, mostramos que o investimento prévio em tecnologia e em informação dotou o parlamento de autonomia visando manter suas atividades.

Palavra-chave: Pandemia; Funcionamento Congressual; Câmara dos Deputados; Novas Tecnologias; Sistema de Deliberação Remota.

\begin{abstract}
March 13 marks the beginning of social withdrawal in Brazil due to the pandemic caused by Covid-19. Four days later, the House of Representatives institutes the Remote Deliberation System (SDR), holding its first virtual session on the 25th of the same month. The article aims to understand the micro process that enabled the resumption of plenary activities of the House so quickly. Through qualitative research and semi-structured questionnaires applied to key actors in the process, we showed that the previous investment in technology and information on the institution provided the parliament with autonomy in order to maintain its activities.
\end{abstract}

Keywords: Pandemic Times; Congressional Functioning; House of Representatives; New Technologies; Remote Deliberation System.

\footnotetext{
${ }^{1}$ É Professora/Pesquisadora Associada dos Cursos de Graduação e Pós-Graduação em Ciência Política da UNIRIO. Doutora em Ciência Política pelo antigo IUPERJ e pós-doutora pelo CILAS/UCSD. Tem experiência nas áreas de Instituições e Políticas Públicas.

${ }^{2}$ É mestre e doutor em Ciência Política pelo antigo Instituto Universitário de Pesquisas do Rio de Janeiro (Iuperj), com estágio pós-doutoral em ciência política na Universidade da Califórnia, San Diego (UCSD). É professor/pesquisador do Instituto de Estudos Sociais e Políticos da Universidade do Estado do Rio de Janeiro (IESPUERJ), onde coordena o Observatório do Legislativo Brasileiro (OLB), o Núcleo de Estudos sobre o Congresso (Necon) e o Grupo de Estudos de Economia e Política (GEEP). Tem publicações na área de estudos legislativos em periódicos nacionais e internacionais.
} 
Resumen: El 13 de marzo marca el inicio del retiro social en Brasil debido a la pandemia causada por Covid-19. Cuatro dias después, La Cámara de los Diputados instituyó el Sistema de Deliberación Remota (SDR), realizando su primera sesión virtual el dia 25 del miesmo mes. El artículo tiene como objetivo compender el microproceso que permitió retomar tan rápidamente lãs actividades plenárias de la Cámara. A través de investigaciones cualitativas y cuestionarios semiestructurados aplicados a actores claves del processo, mostramos que La inversión previa em tecnologia e infromación há dotado AL parlamento de autonomia para mentener SUS actividades.

Palabras clave: Pandemia; Funcionamiento del Congreso; Cámara de los Diputados; Nuevas tecnologias; Sistema de Deliberación Remota.

\section{Introdução}

A experiência legislativa brasileira durante a atual crise pandêmica não apenas configura elemento político básico de conjuntura. É também fenômeno de grande interesse no debate acadêmico sobre a inserção do Congresso no processo mais denso de produção de políticas. Desde os estudos iniciais de Figueiredo e Limongi (1999), passando pelo diagnóstico do funcionamento das comissões de Pereira e Mueller (2000) e análise da produção endógena de leis ao Congresso de Amorim Neto e Santos (2003), algum consenso existia sobre a liderança do Executivo, o presidente e seus ministros, na organização do processo decisório em torno de políticas públicas centrais para o país ${ }^{3}$. A proposta do trabalho parte do artigo clássico de Abranches (1988), segundo o qual o funcionamento do sistema depende da iniciativa do presidente em formar uma base de apoio operacional no parlamento, girando em torno de coalizões com os principais partidos. Uma vez decidida a formação da coalizão, Legislativo, Executivo, partidos e ministros teriam os instrumentos institucionais necessários à boa condução do governo. O contrafactual seria a entropia, paralisia decisória ou, no limite, a destituição do presidente. Ou seja, não havia no horizonte de hipóteses prováveis a possibilidade de o Congresso, ele mesmo, tornar-se o lócus central de produção de políticas públicas para o país.

Não obstante, já de algum tempo o Congresso Nacional vem tornando-se o principal legislador no Brasil, como indica o excelente trabalho de Almeida (2018), e suas atividades fortemente ancoradas nas capacidades informacionais das Comissões permanentes e da estrutura de assessoria e consultoria legislativas (SANTOS; CANELLO, 2016). O que veremos neste artigo reforça essa tese. Ou seja, no momento em que se instalou a crise sanitária da Covid-19 o Legislativo brasileiro contemporâneo, mais especificamente, a Câmara dos Deputados, assumiu um protagonismo no processo de tomada de decisão, vis-à-vis o Executivo, que viabilizou as atividades legislativas de forma remota, servido, inclusive, de inspiração para parlamentos em todo o mundo. É sobre esse ponto que versa o artigo que se segue. ${ }^{4}$

\footnotetext{
${ }^{3}$ Para uma resenha recente da enorme e boa bibliografia que surge a partir dos anos 1990 em torno do Legislativo, ver Figueiredo e Santos (2016).

${ }^{4}$ Para mais informações sobre o funcionamento do Legislativo brasileiro durante o período remoto, tais como temas
} 


\section{Primeiros Passos.}

Nosso objetivo no artigo é explicitamente descritivo e não explicativo. Buscamos apoio na hipótese de ter havido uma evolução institucional envolvendo o Legislativo brasileiro no sentido de torná-lo mais pró-ativo no processo decisório em políticas públicas (ALMEIDA, 2018), tendo o contexto da pandemia como objeto de investigação, e, além disso, de ser tal evolução institucional resultado, entre outros fatores, do investimento em assessoria e informação (SANTOS; CANELLO, 2016). Nesse sentido, não haverá teste de hipótese, nem nova explicação sobre o funcionamento da Câmara dos Deputados e estranho seria caso houvesse, uma vez que a experiência da pandemia tem início faz apenas alguns meses. Acreditamos, contudo, que a crônica da reação de deputadas e deputados ao novo ambiente político gerado pela crise sanitária fornece material rico para futuras explanações, mais rigorosas e dotadas de contornos "científicos" mais bem definidos. Senão vejamos.

A ação legislativa número 1 no Brasil da pandemia foi a própria decisão de manter em funcionamento o Congresso Nacional. No fim do ano de 2019 e início de 2020 o mundo começou a tomar conhecimento do poder devastador do SARS-CoV-2, vírus causador da Covid-19, também conhecido como Coronavírus ${ }^{5}$. Os primeiros casos da doença ocorreram na cidade de Wuhan, na China, no início de dezembro de 2019, sendo enviada notificação à Organização Mundial de Saúde (OMS) no final daquele mês. O Brasil iniciou o ano de 2020 solicitando à OMS esclarecimentos sobre a notificação e, dias depois, a Organização publicou seu primeiro comunicado de alerta sobre o surto e anunciou mais de 40 casos de "pneumonia por causas desconhecidas" na China, com uma morte, além de dois casos de pacientes com passagem em Wuhan, um na Tailândia e outro no Japão. No dia 10 de janeiro, o Comitê de Monitoramento de Eventos do Ministério da Saúde brasileiro foi acionado e, seis dias depois, este mesmo ministério publicou a primeira informação sobre seu conhecimento da doença. No dia 20 de janeiro a OMS e a Organização Panamericana de Saúde (OPAS) se reuniram para definir uma estratégia internacional de resposta, sendo divulgado no dia seguinte, o primeiro Boletim Epidemiológico da OMS com a indicação de risco moderado. No dia 22 foi ativado o Comitê de Operações de Emergência (COE) em nível 1 de alerta, sendo elevado para o nível 2 cinco dias depois. No dia 24, o número de casos da doença já superava os 800, com 25 mortes, incluindo a primeira fora da China. No penúltimo dia do mês de janeiro, a OMS alterou seu posicionamento e elevou a indicação de risco para "alto", declarando Emergência Internacional.

Na sequência dos acontecimentos, o Brasil acionou no dia 31 de janeiro, o Grupo Executivo Interministerial, com a primeira reunião realizada no dia 3 de fevereiro, mesmo dia

\footnotetext{
abordados e quantitativo de matérias, ver análises do Congresso Remoto (www.congressoremoto.org.br/analises).

${ }^{5}$ Ver https://coronavirus.saude.gov.br/linha-do-tempo/\#dez2019

http://corona.dourados.ms.gov.br/index_admin.php?class=NeaArtigoView\&id=4
} 
em que o país declarou Emergência de Saúde Pública de Importância Nacional (ESPIN). Um dia depois, no dia 4, o Ministério da Saúde enviou ao Congresso Nacional o Projeto de Lei de Quarentena, sendo aprovado em dois dias pelo Congresso Nacional. No dia 5 do mesmo mês foi realizada a missão de repatriamento dos 34 brasileiros que viviam na cidade de Wuhan, ocorrendo, um dia depois, uma reunião da Comissão Intergestores Tripartite (CIT) com secretários de saúde de estados e capitais. Três eventos importantes acontecem no dia 7 de fevereiro. O primeiro deles foi a sansão presidencial do projeto de lei da quarentena aprovado pelo Congresso no dia anterior; o segundo, a decolagem do voo trazendo os brasileiros da China; e o terceiro, a capacitação técnica de representantes de nove países das Américas do Sul e Central, realizada pelo Ministério da Saúde e pela a Fundação Oswaldo Cruz (Fiocruz), para diagnóstico laboratorial do novo vírus. No dia 9 de fevereiro desembarcam no Brasil as 58 pessoas envolvidas na Operação de Regresso dos brasileiros da China.

Até o dia 10 de fevereiro já tinham sido registrados mais de 40 mil casos no mundo, com 454 deles em outros 24 países, e mais de mil mortes, sendo as duas primeiras fora da China, em Hong Kong e nas Filipinas. ${ }^{6}$ Com a avaliação da ocorrência de poucos casos fora do território chinês e número de infectados crescendo menos, a OMS definiu, no dia 14 de fevereiro, o surto da Covid como 'controlado', posição alterada 10 dias depois, quando se observou um aumento exponencial de casos externos à China, com os maiores números sendo registrados na Itália - que passou de 79 casos para $222 \mathrm{em}$ apenas dois dias - e no Irã - que contabilizou 12 mortes e fechou as fronteiras. Ao todo, nesse período, quase 80 mil casos foram confirmados, sendo mais de 2 mil em outros 31 países, e 2.600 mortes, 35 delas fora da China. Diante desses números, a OMS declarou, então, que os países deveriam se preparar para uma possível pandemia.

No Brasil, foram apresentadas ações de enfrentamento ao vírus durante a reunião dos ministros da Saúde do MERCOSUL, em Assunção, no Paraguai, no dia 19 de fevereiro. No dia 21, o alerta para casos suspeitos da doença no mundo atingiu mais 7 países além da China, subindo para 16 países três dias depois. O primeiro caso de coronavírus no país foi confirmado no dia 26 de fevereiro, na cidade de São Paulo, em um paciente de 61 anos com histórico de passagem pela Itália. No mês seguinte, dia 9 de março, o Ministério da Saúde passou a adotar as novas recomendações da OMS, como realização de testes de Covid em pacientes internados com síndrome respiratória grave. Em 11 do mesmo mês, a Organização definiu o surto como pandemia, período no qual o número de casos subiu para 118 em 114 países, com mais de quatro mil mortes, sendo $90 \%$ dos casos localizados na China, Itália, Irã e Coreia do Sul. Um dia depois, o Ministério da Saúde brasileiro, seguindo a orientação da OMS, regulamentou e

\footnotetext{
${ }^{6} \mathrm{O}$ primeiro caso da doença nos Estados Unidos, país líder no número de casos e mortes, foi anunciado no dia 21 de janeiro.
} 
publicou no Diário Oficial da União (DOU) os critérios de isolamento e quarentena a serem aplicados e seguidos pelas autoridades de saúde locais. O objetivo era evitar a dispersão do vírus pelo país e o colapso o Sistema Único de Saúde (SUS) por superlotação nos hospitais públicos. Posteriormente, no dia 13, recomendou a antecipação de férias escolares, a suspensão de eventos e o isolamento de viajantes internacionais. Quatro dias depois foram anunciadas as primeiras mortes por Covid no país, primeiro um homem de 62 anos no estado de São Paulo, e, horas depois, uma mulher de 63 anos e um homem de 69 anos, no estado do Rio de Janeiro.

Como vimos, o dia 13 de março marca o início do afastamento social no Brasil. Quatro dias depois, no dia 17, a Câmara dos Deputados publica a Resolução nº 14/2020 e institui o Sistema de Deliberação Remota (SDR) ${ }^{7}$. O SDR foi criado para viabilizar o funcionamento da Casa durante a crise sanitária e econômica relacionada ao Covid-19, permitindo a discussão e votação de matérias, preferencialmente voltadas à emergência de saúde pública, sujeitas à apreciação do plenário de forma remota. As plataformas digitais que serviram de base para o sistema permitiram os debates entre os parlamentares por áudio e vídeo, inclusive por smartphones, via aplicativo chamado Infoleg. A ferramenta previu ainda a publicação desses áudios e vídeos, de forma simultânea ou gravada, nos canais de mídia institucional, TV, Youtube ou através das mídias sociais dos parlamentares. ${ }^{8}$ Todas as informações sobre as matérias a serem votadas, a orientação de voto das lideranças partidárias, e, finalmente, o voto do parlamentar, são viabilizados pelo aplicativo. Para ter acesso a esse aplicativo, foi necessária a realização de novos cadastros pelos parlamentares, com registros de novos e-mail e senha, diferentes daqueles utilizados na plataforma interna da Câmara. A convocação das sessões acontece com antecedência mínima de vinte e quatro horas, salvo se realizadas em sequência. As sessões realizadas por meio do SDR são consideradas sessões deliberativas extraordinárias, constando em ata a informação expressa de que as deliberações foram tomadas em ambiente virtual. $^{9}$

Uma das principais preocupações tecnológicas em torno da criação do Sistema de Deliberação Remota foi a garantia da segurança dos trabalhos virtuais, tanto para os deputados, quanto para a legitimidades das decisões, desde o debate até o voto final. Pensando nisso, a Resolução 14 previu, e o sistema do aplicativo Infoleg garantiu, os seguintes procedimentos: sigilo do voto do parlamentar até a totalização da votação e anúncio do resultado;

${ }^{7}$ https://www2.camara.leg.br/legin/fed/rescad/2020/resolucaodacamaradosdeputados-14-17-marco-2020-789854publicacaooriginal-160143-pl.html.

${ }^{8}$ A transmissão das seções e/ou da sua gravação nos ambientes virtuais é veda nos casos de sessões secretas, que são aquelas que deliberam sobre projeto de fixação ou modificação dos efetivos das Forças Armadas; declaração de guerra ou acordo de a paz; e passagem ou permanências de forças estrangeiras pelo território nacional (Incisos I, II e III do parágrafo único do Art. 92 do Regimento Interno da Câmara dos Deputados).

${ }^{9}$ A média do quórum em sessões deliberativas na Câmara dos Deputados subiu de 445 para 503 no período remoto, com a ressalva de que o quórum é medido duas horas antes da sessão, sem verificação posterior. (www.congressoremoto.org.br/analises) 
irretratabilidade do voto uma vez encerrada a votação; garantia do sigilo dos dados biométricos dos parlamentares; proclamação do processo de votação, totalização dos votos e registro dos resultados de votação através dos sistemas institucionais da Câmara dos Deputados; possibilidade de soluções ao gerenciamento de áudio e vídeo das sessões por meio de plataformas comerciais, desde que estas atendessem aos requisitos definidos pela Resolução; utilização dos sistemas operacionais IOS ou Android nos smartphones, bem como habilitação prévia dos mesmos; verificação em duas etapas para a primeira autenticação do dispositivo; acesso simultâneo de todos os deputados e da Secretaria Geral da Mesa à sessão, mediada pelo presidente da Casa; e, finalmente, funcionamento ininterrupto da sessão virtual, supervisionada pela Diretoria de Inovação e Tecnologia da Informação da Câmara.

$\mathrm{O}$ artigo tem por objetivo daqui por diante fornecer uma descrição do micro processo, em vários momentos, propriamente tecnológico e informacional, que viabilizou a retomada das atividades de plenário da Câmara dos Deputados tão rapidamente, desde a decretação do afastamento social em todo o território nacional, no dia 13 de março, até a realização da sua primeira sessão virtual, 12 dias depois, dia 25 de $\operatorname{março~}{ }^{10}$ Quando exatamente e por que houve a clareza, na Câmara dos Deputados, da necessidade de se avançar com o sistema de deliberação remota? De que maneira, e se ocorreu, a experiência internacional influenciou o processo brasileiro de realização do sistema remoto? Houve autonomia nesse processo ou se seguiu experiências internacionais já em andamento? A criação e uso do sistema de deliberação remota resultaram de iniciativas e sugestões feitas aos políticos pela Diretoria de Tecnologia e Informação da Câmara dos Deputados; resultaram de uma demanda dos políticos ocupantes da Mesa Diretora e/ou lideranças partidárias; ou foram uma via de mão dupla, com intensa cooperação e coordenação entre essas duas instâncias? Ao entrevistar atores chaves no processo e, assim, conseguir as respostas para tais questões, nossa reflexão visa não ao teste sistemáticos de novas e velhas hipóteses, mas apenas apontar direções possíveis para o debate político e acadêmico em torno do Legislativo nos tempos de pandemia. Acreditamos que por essa via também estaremos lançando luzes sobre a dinâmica institucional da Câmara no mais longo prazo (ALMEIDA, 2018).

\footnotetext{
${ }^{10}$ A ciência política brasileira não tem se debruçado com a devida atenção sobre o tema do uso das mídias digitais como forma de preencher as atividades de representação política. Exceção importante encontra-se no trabalho desenvolvido por Sérgio Soares Braga e sua equipe na Universidade Federal do Paraná (UFPR). Já são vários artigos publicados e teses defendidas. Cito aqui duas produções recentes Carlomagno, Braga e Wisse (2019) e Carlomagno e Braga (2019). Outra exceção importante encontra-se em Faria (2015), um dos nossos informantes.
} 


\section{Entrevistas e Depoimentos de Atores Chaves no Processo}

Realizamos entrevistas semi-estruturadas por e-mail com atores-chaves da Câmara dos Deputados envolvidos na execução do Sistema de Deliberação Remota, ferramenta que viabilizou as atividades legislativas no período da quarentena. São eles: Patricia Gomes Rego de Almeida, diretora adjunta da Diretoria de Inovação e Tecnologia da Informação, Cristiano Ferri Soares Faria, executor de projetos em inovação cívica, Marcus Vinícius Chevitarese Alves, também da Diretoria de Inovação e pesquisador do Centro de Formação e Aperfeiçoamento doa Recursos Humanos da Câmara dos Deputados (CEFOR), e Marcelo Calero, Deputado Federal, pelo Cidadania, do Rio de Janeiro. As entrevistas foram compostas por perguntas abertas cujo conteúdo fora previamente discutido com os respondentes. A escolha desta e destes respondentes decorreu da posição que ocupam no processo de sofisticação tecnológica da Casa Legislativa (no caso de Almeida, Alves e Faria), no debate acadêmico e institucional sobre tal processo (casos de Almeida, Alves e Faria) e na participação como representante na decisão final sobre políticas (caso de Calero).

Com relação ao momento em que ficou clara a necessidade de se avançar em um sistema de deliberação remota para garantir as atividades legislativas da Câmara dos Deputados, nossos entrevistados informaram que foi a partir da observação do avanço da discussão sobre o assunto em democracias acometidas pela Covid antes do Brasil. Nesse momento, ainda no mês de fevereiro, o Secretário-Geral da Mesa da Casa começou a analisar a possibilidade e amadurecer a ideia. Desta forma, de acordo com um dos entrevistados, a Câmara dos Deputados agiu tão rapidamente na realização do sistema de deliberação remota que é possível afirmar que as experiências internacionais foram influenciadas pelo processo brasileiro, e não o contrário. A partir de então, o modelo da normatização, a tecnologia utilizada e a adaptação ao novo formato de atividade legislativa foram construídas conjuntamente, com base em muita troca de informações entre o Legislativo brasileiro e os parlamentos internacionais.

A agilidade da Câmara na execução do SDR, do ponto de vista comparado com outras democracias, pode ser explicada, segundo as entrevistas, por alguns fatores. Em primeiro lugar, pela existência de recursos humanos tecnológicos especializados, além de recursos materiais substanciais (o orçamento anual da Câmara é um dos maiores dentre parlamentos do mundo). Em segundo lugar, pela vontade política por parte do Presidente da Casa e da Mesa Diretora, "tendo em vista o papel essencial do Poder Legislativo dentro do sistema de freios e contrapesos no atual contexto político institucional brasileiro, sendo o presidente Rodrigo Maia o líder desse processo". Por último, a certa tradição de iniciativas de inovação tecnológica pela Câmara desde os anos 2000, através dos núcleos tecnológicos espalhados pela Casa.

Uma das principais preocupações da utilização do sistema remoto, como já narrado anteriormente, era com o arcabouço legal que amparasse a validade das deliberações das sessões 
virtuais. Foi apontado como grande desafio viabilizar tecnologicamente o trabalho remoto, com mais de 500 participantes, cuja dinâmica se aproximasse de uma sessão presencial. Como se tratava de uma realidade totalmente nova, as adaptações e ajustes em torno da comunicação com os parlamentares, seja para instruções, seja no suporte às sessões, eram ajustadas diariamente, a cada nova versão. "Nosso processo de construção tecnológica foi incremental, o que nos permitiu oferecer uma solução integrada que contemplasse, em um aplicativo, desde o registro de presença, consulta da orientação dos líderes de partido, o voto, inscrição em lista de oradores para diferentes momentos da sessão, até o painel de resultados".

Para assegurar a transparência, os dados continuaram a ser publicados no portal de dados abertos da Câmara, respeitando-se os mesmos formatos originais. O processo de gestão de mudanças requereu o envolvimento de equipes multidisciplinares, desde servidores experientes do rito legislativo aos profissionais da área de tecnologia, que se alternavam em turnos durante todo o dia e realizavam testes quando não havia sessão. Com relação à garantia da segurança e a legitimidade do processo decisório remoto, foi criada, então, a Resolução $n^{\circ}$ 14/2020, que, como vimos, instituiu o Sistema de Deliberação Remota da Câmara. A equipe técnica, segundo entrevista, discutiu exaustivamente o tema da legalidade das decisões em ambiente virtual, dentro do tempo que dispunha, e foram tomadas medidas no sentido de garantir a autoria do voto. Assim, uma das medidas incorporada pela Resolução 14 foi o cadastro de identificação do celular de cada parlamentar para que o sistema pudesse identificar com segurança se aquele dispositivo estaria ou não autorizado a emitir voto. Com relação à adaptação dos deputados ao sistema, nos foi informado que não pareceu ter havido grandes dificuldades, uma vez que já se utilizava o Infoleg, aplicativo para smartphones e tablets que traz informações sobre as atividades legislativas da Câmara. Além disso, foram feitas algumas rodadas de testes e simulações como treinamento, no intuito de antecipar eventuais dificuldades na manipulação do sistema.

Pelas informações coletadas a partir das entrevistas podemos afirmar que a criação do Sistema de Deliberação Remota da Câmara dos Deputados não partiu do zero. A necessidade de se viabilizar um processo legislativo digital já fazia parte da estratégia digital da Casa. Encontrava-se em tramitação, desde dezembro de 2019, a Resolução $n^{\circ}$ 12/2019 ${ }^{11}$, que estabelece o processo legislativo digital na Câmara. Tal matéria foi apontada como base para as decisões que vieram a ser executadas. Quando o afastamento social foi deflagrado e a importância de se manter as atividades deliberativas da Casa no período de isolamento detectada, a Secretaria Geral da Mesa e a Presidência da Casa solicitaram à Diretoria de Inovação e Tecnologia da Informação avaliação sobre viabilidade técnica de se acelerar

$11 \quad$ Originalmente, $\quad$ PRC $\quad$ 113/2019: $\quad$ https://www.camara.leg.br/proposicoesWeb/ prop mostrarintegra;jsessionid=826D98BB91EF1EA5D42CD343E65A2AF5. proposicoesWebExterno2? codteor=18 
algumas ações previstas na transformação digital da Casa. Como essa diretoria já contava com vários módulos tecnológicos de sistemas dirigidos a automação do processo legislativo, frutos de planejamento estratégico anterior, tal como o Infoleg, a construção de uma solução para deliberações remotas viabilizou-se de maneira natural. O que não havia era a possibilidade de se votar remotamente, adaptação feita em um prazo bastante exíguo (cerca de dez dias). Em outras palavras, o SDR já estava engatilhado como projeto antes da pandemia. A quarentena foi apenas, como relatado, uma janela de oportunidade que se abriu. "Certamente, sem a estratégia e o investimento dos servidores em um modelo digital que permitisse agilidade, transparência, rastreabilidade e alcance nacional, não seria possível ter implantado o contingenciamento do funcionamento da democracia representativa nesse momento de pandemia", relata um de nossos entrevistados.

$\mathrm{Na}$ entrevista com Cristiano Ferri Faria, executor de projetos em inovação cívica da Câmara dos Deputados e que esteve envolvido no laboratório de inovação cidadã da Casa, o LabHacker ${ }^{12}$, foi perguntado se a experiência teria servido com uma espécie de origem tecnológica do SDR. Sua resposta foi que não diretamente e nos informou que o LabHacker surgiu no contexto dos movimentos de junho de 2013 como uma resposta do Congresso ao clamor popular por maior abertura e participação no processo legislativo federal. Além disso, serviu como um instrumento hacker para abrir uma outra frente de desenvolvimento tecnológico à parte do departamento tecnológico da Câmara, hoje responsável pelo SDR. Nesse sentido, continua, o LabHacker incorporou mecanismos de inovação aberta e desenvolvimento em rede (com a participação de parlamentares, inclusive) para projetos tecnológicos e outras inovações não tecnológicas voltadas a um objetivo bem específico: a política de parlamento aberto. Por outro lado, contribuiu para gerar uma tensão em relação ao Departamento de Tecnologia e Inovação, como uma competição construtiva, como se esse Departamento perdesse o monopólio do desenvolvimento tecnológico.

Além da visão técnica sobre a experiência brasileira no processo de execução do sistema de deliberação remota, é importante destacarmos também a visão política. Na percepção do deputado Marcelo Calero, questionado sobre o tipo de preocupação política que teria surgido entre os parlamentares com o SDR, destacou a capacidade de influência, com isonomia, dos partidos sobre os mais diversos processos legislativos. Seu relato indica que essa preocupação foi sendo mitigada na medida em que se intensificaram as reuniões de líderes, que permaneceram presenciais, e em que se tornava claro que a distância física não impediria as

$15743 \&$ filename $=\mathrm{PRC}+113 / 2019$

12 "O LABHacker é o laboratório de inovação cidadã da Câmara dos Deputados e atua em três temas: transparência, participação e cidadania, com projetos colaborativos e experimentais. O laboratório também tem o objetivo de articular uma rede entre parlamentares, servidores públicos, hackers cívicos e sociedade civil que contribua para a cultura da transparência e da participação social por meio da gestão de dados públicos". (http://labhackercd.leg.br/) 
negociações em torno das matérias, a princípio, relacionadas apenas ao combate à pandemia do novo coronavírus, prioridade essa que, chama atenção, começa a ser revista com a deliberação de outras matérias não relacionadas à crise sanitária. Perguntado sobre o posicionamento das organizações da sociedade civil no processo de execução do SDR, relatou que houve uma percepção rápida da importância da deliberação remota nesse momento, uma vez que a alternativa seria a interrupção do funcionamento do parlamento, "algo que somente aconteceu durante o governo militar e que se configura como inaceitável no período atual".

Finalmente, questionado sobre se houve consciência do grau de centralização das atividades na Mesa e nos líderes no que diz respeito às informações essenciais para tomada de posicionamento e voto, Calero respondeu que sim, houve esta consciência: "Esse aspecto foi repisado pela presidência da Câmara e discutido internamente nos partidos. Os gabinetes tiveram de se reinventar, para que suas assessorias também pudessem centralizar a variedade de debates internos dos partidos sobre as matérias em pauta. Com efeito, muito do trabalho de análise feito originalmente pelas lideranças passou a ser feito, em certa medida, pelo próprio gabinete dos parlamentares, especialmente em matérias que tradicionalmente se identificam divergências entre o gabinete e o posicionamento do partido. Contribuiu para essa centralização o fato de as comissões parlamentares não estarem funcionando. Como se sabe, as comissões são espaços de pulverização temática, na medida em que abrigam discussões mais detidas e específicas e, por isso, é o locus onde os parlamentares conseguem maior protagonismo em sua atuação, independentemente do tamanho das bancadas que integram".

Sobre cenários futuros para os trabalhos legislativos pós-pandemia, alguns foram vislumbrados, como a consolidação do parlamento virtual, com deliberações de plenário e comissões, debates (lives), assessoria e atendimento de gabinete ocorrendo em plataforma remota. Além disso, essa nova prática atenderia à narrativa pública em relação à redução de gastos com o trabalho legislativo, como eletricidade, água, café, limpeza etc. Por outro lado, aponta um dos entrevistados, a transformação para o ambiente digital pode encontrar resistência natural da "velha política", que enfrenta dificuldade de adaptação ao mundo online, além da resistência política em virtude de potencial diminuição de recursos de viagem semanais dos parlamentares.

Em síntese, retomando as perguntas do artigo, as entrevistas nos permitiram concluir que, em primeiro lugar, a necessidade de se avançar com o sistema de deliberação remota na Câmara dos Deputados foi confirmada com a recorrente observação de iniciativas tomadas nesse sentido por outras democracias já acometidas pela pandemia e pelo distanciamento social. Sobre esse ponto, houve uma aproximação entre os parlamentos espalhados pelo mundo e os trabalhos passaram a ser construídos em conjunto, com troca de informações e experiências. Contudo, e já remetendo à segunda pergunta do artigo, a Câmara dos Deputados brasileira encontrava-se, naquele momento, em um estágio bastante adiantado de construção de 
ferramentas tecnológicas que permitissem o trabalho remoto. Apenas alguns ajustes tornaram-se necessários para colocá-las em prática, o que foi feito em curto espaço de tempo. Desta forma, o Brasil, embora acometido pela pandemia tardiamente, é visto mais como influenciador das experiências internacionais do que o contrário. No que se refere à terceira pergunta, sobre se o legislativo brasileiro teria atuado com autonomia nesse processo ou teria seguido experiências internacionais já em andamento, houve parceria na troca de experiências entre parlamentos de diversas democracias, como sinalizou um dos entrevistados, mas as iniciativas tecnológicas brasileiras encontravam-se em estágio mais adiantado, o que nos permitiu atuar com autonomia. Finalmente, sobre o protagonismo da criação do SDR na Câmara, se da Diretoria de Tecnologia e Informação, dos políticos ocupantes da Mesa Diretora e/ou lideranças partidárias, ou uma via de mão dupla, pelas entrevistas entendemos que os ocupantes da Mesa, centrada na figura do seu presidente, solicitaram a execução do sistema remoto à Diretoria de Tecnologia que, por sua vez, atendeu à demanda em curto espaço de tempo pelo fato de, como narrado, já dispor de ferramentas.

\section{Conclusão}

A crônica do processo de criação e institucionalização do SDR, com foco na Câmara, reforça a hipóteses de um Legislativo dotado de forte estrutura informacional, capaz de, autonomamente, se organizar de forma a manter ininterrupto o processo decisório em torno da agenda pública. Várias e centrais políticas válidas durante a pandemia foram ali gestadas, aparentemente, à revelia das preferências do presidente da República e seus ministros. Os exemplos do auxílio emergencial e do FUNDEB são apenas os mais gritantes dentro de um conjunto massivo de proposições e emendas constitucionais. Ademais, o atual o presidente foi o que, desde Fernando Collor e com exceção do curto segundo mandato de Dilma Rousseff, mais derrotas sofreu em plenário, sendo que este cenário só piora após a $\mathrm{SDR}^{13}$.

Fica claro, portanto, que o SDR foi um desdobramento institucional, embora não prédeterminado e necessário, ex ante bastante provável, dadas as capacidades tecnológicas instaladas na Câmara dos Deputados e as inclinações e ambições políticas das lideranças legislativas eleitas para presidir esta Casa. Sendo assim, a experiência legislativa brasileira na pandemia poderá ter como consequência a revisão conceitual da ciência política sobre a inserção e dinâmica institucional do Congresso no processo político brasileiro. Mas essa experiência coloca desafios para além do debate conjuntural e acadêmico. Basicamente duas são as questões, obviamente entrelaçadas, de muito interesse: qual o modelo a ser seguido no

\footnotetext{
${ }^{13}$ Para análises das diversas mudanças ocorridas no processo decisório legislativo a partir do SDR, ver os sites do Congresso Remoto ( $\underline{w w w . c o n g r e s s o r e m o t o . o r g . b r) ~ e ~ d o ~ O b s e r v a t o ́ r i o ~ d o ~ L e g i s l a t i v o ~ B r a s i l e i r o ~(w w w . o l b . o r g . b r) . ~}$
} 
momento pós pandemia? Como se dará o relacionamento da sociedade com o parlamento? ${ }^{14}$

Como sabemos, em relação ao primeiro ponto, a composição individual do Congresso é distinta do efeito agregado de seu funcionamento, resultado de fatores que escapam ao perfil das pessoas que ocupam a instituição. A capacidade tecnológica do Legislativo é fruto de um investimento secular da sociedade em sua democracia, sendo os donos das cadeiras resultantes de escolhas eleitorais feitas em circunstâncias históricas específicas. Até que ponto os e as parlamentares donas dos atuais e futuros mandatos manterão a trajetória institucional de autonomia tão evidente durante a pandemia é questão a se acompanhar de perto. Com relação à segunda pergunta, cabe pensar se a atual experiência legislativa de fato tem representado melhor a sociedade, a despeito do cancelamento das comissões e de que maneira as organizações da sociedade civil podem aumentar sua intervenção no processo decisório. Embora a decisão de manter o funcionamento da Câmara (e, logo em seguida do Senado) em março de 2020 tenha sido crucial para a democracia, e a capacidade tecnológica e informacional instalada variável crucial nesta direção, escassos ainda são os elementos para um diagnóstico a respeito de eventual aumento em sua representatividade.

\section{Referências}

ABRANCHES, Sergio. Presidencialismo de Coalizão: o dilema institucional brasileiro. Revista Dados, v. 31, n. 1, p. 5-34, 1988.

ALMEIDA, Acir. Governo Presidencial Condicionado: delegação e participação legislativa na Câmara dos Deputados. 2018. Tese (Doutorado em Ciência Política) - Instituto de Estudos Sociais e Políticos, Universidade do Estado do Rio de Janeiro-UERJ, 2018.

AMORIM NETO, Octavio; SANTOS, Fabiano. The Inefficient Secret Revised: The Legislative Input and Output of Brazilian Deputies. Legislative Studies Quarterly, v. 28, n. 4, p. 449-479, 2003.

CARLOMAGNO, Márcio; WISSE, Fernando; BRAGA, Sérgio. Gabinetes digitais: o papel da comunicação online na rotina parlamentar. E-Legis: Revista Eletrônica do Programa de PósGraduação da Câmara dos Deputados, v. 11, n. 26, p. 104-132, 2019.

CARLOMAGNO, Márcio; BRAGA, Sérgio. As assessorias de mídias digitais dos parlamentares brasileiros: organização e profissionalização na Câmara dos Deputados. Teoria \& Sociedade, Belo Horizonte, v. 26, p. 150-178, 2019.

FARIA, Cristiano. Parlamento Aberto na Era da Internet: Pode o povo colaborar com o Legislativo na elaboração de leis?. Brasília: Câmara dos Deputados, 2015.

\footnotetext{
${ }^{14}$ Alguns "gargalos" do processo de deliberação remota são: agilidade na aprovação das matérias em plenário, resultando em escassez de debate; pouca circulação de informação sobre a matéria, partindo-se logo para a votação; ausência de presença física nos gabinetes, plenário e comissões para aprofundamento das discussões; votações simbólicas sempre que há consenso no Colégio de Líderes, sem que haja debate sobre a matéria; ausência de participação social, ainda que virtual. (Ver Boletim 1 - congressoremoto.org.br/analises)
} 
FIGUEIREDO, Argelina; LIMONGI, Fernando. Executivo e Legislativo na Nova Ordem Constitucional. Rio de Janeiro: Editora da FGV, 1999.

FIGUEIREDO, Argelina; SANTOS, Fabiano. Estudos Legislativos no Brasil. In: AVRITZER, Leonardo; MILANI, Carlos; BRAGA, Maria do Socorro. A Ciência Política no Brasil, 19602015. Rio de Janeiro: Editora FGV, 2016.

PEREIRA, Carlos; MULLER, Bernardo. Uma Teoria da Preponderância do Poder Executivo: o sistema de comissões no Legislativo brasileiro. Revista Brasileira De Ciências Sociais, v.15, n. 43 , p. $45-67,2000$.

SANTOS, Fabiano; CANELLO, Júlio. Comissões Permanentes, Estrutura de Assessoramento e o Problema Informacional na Câmara dos Deputados. Dados: Revista de Ciências Sociais, v. 59, n.4, p. 1127-1168, 2016. 